\title{
A simple and easy home-based pulmonary rehabilitation programme for patients with Chronic Lung Diseases
}

\author{
Joo Ock Na1, Dong Soon Kim¹, Seong Ho Yoon1, Yang Jin Jegal1, \\ Woo Sung Kim¹, Eung Suk Kim¹, Myung Wha Kim²
}

ABSTRACT: A simple and easy home-based pulmonary rehabilitation programme for patients with Chronic Lung Diseases. Joo Ock Na, Dong Soon Kim, Seong Ho Yoon, Yang Jin Jegal, Woo Sung Kim, Eung Suk Kim, Myung Wha Kim.

Background and Aim. To develop a simple and easy home-based pulmonary rehabilitation programme and investigate its effectiveness.

Methods. Patients with stable chronic lung disease were divided into a rehabilitation group $(n=25)$ and a control group $(n=18)$. Rehabilitation consisted of education and 12 weeks of enforced aerobic and musclestrengthening exercises. Aerobic exercise training was performed mostly by walking based on the functional capacity of the patients assessed by the maximal incremental exercise test. Patients visited hospital every two weeks for evaluation and a new exercise regimen.
Results. Five patients dropped out of the rehabilitation group but three were due to development of unrelated diseases, five controls did not co-operate in the second evaluation. After 12 weeks of rehabilitation, exercise capacity (maximum work load and $\mathrm{VO}_{2} \mathrm{max}$ ), exercise endurance, 6-minute walking distance, and quality of life measured by the St. George Respiratory Questionnaire had significantly improved in the rehabilitation group but not in the controls. At a follow-up evaluation one year after the rehabilitation, some exercise parameters were still significantly higher than baseline in the rehabilitation group.

Conclusions. We developed a simple home-based pulmonary rehabilitation programme, which seems to be clinically feasible and effective.

Monaldi Arch Chest Dis 2005; 63: 1, 30-36.

Keywords: Home-based pulmonary rehabilitation; COPD; exercise capacity and endurance; quality of life; effectiveness.

1 Division of Pulmonary and Critical Medicine,

2 Department of Internal Medicine and Health Promotion Center, Asan Medical Center, University of Ulsan, College of Medicine, Seoul, Korea.

Correspondence: Dong Soon Kim, M.D. Division of Pulmonary and Critical Care Medicine, Department of Internal Medicine, University of Ulsan College of Medicine, Asan Medical Center, 388-1 Pungnap-dong, Song pa-gu, Seoul 138-600, Korea; email:dskim@amc.seoul.kr

This work was supported by the Research Fund of Korean Institute of Health and Social Affairs.

\section{Introduction}

It is well known that pulmonary rehabilitation improves dyspnoea on exertion, exercise capacity and quality of life. There is evidence to show that it also reduces the use of health services like hospital admission frequency and duration, exacerbation rate and general practitioner home visits by patients with chronic lung diseases, especially Chronic Obstructive Pulmonary Disease (COPD) [1-4]. Therefore COPD guidelines include rehabilitation as an important treatment and a new revision of GOLD guideline recommends it for all COPD patients with FEV less than $80 \%$ predicted [5]. The rehabilitation programmes can be carried out on both inpatient and outpatient bases. The inpatient programme is the most intensive and comfortable for the patients, but also the most expensive. For the out- patient programmes to be effective, the patient must go to the hospital frequently, which is a great burden on the patients and their families. Furthermore many studies have reported that the benefits achieved declined progressively after the rehabilitation programme had been completed [6-10]. Therefore, there is a need for a more cost-effective and long-lasting method and home-based programmes have a definite advantage. However, there are only a few reports on home-based programmes, and some are very complicated with close supervision of local physiotherapists or nurses [11-16].

The aims of this study were to develop a simple home-based rehabilitation programme that could be adopted easily by patients without the need for special equipment, and to investigate its short- and long-term (one year) effectiveness in terms of exercise capacity and quality of life. 


\section{Methods}

\section{Patients and Study Design}

The study subjects were 43 patients (rehabilitation group: 25 and control: 18 ). All patients were male. Their $\mathrm{FEV}_{1}$ was less than $65 \%$ predicted without reversibility. All patients had dyspnoea on exertion, which limited their ordinary activity, but they were in a stable condition with medical treatment (home oxygen therapy for two patients) at the time of inclusion. Patients with evidence of heart disease, intermittent claudication, muscularskeletal disorders, or other disabling disease that could limit the rehabilitation programme were excluded. It was performed as a prospective controlled design but not strictly randomised because the effect of pulmonary rehabilitation is so obvious that it may be unethical to have a control group. However, many of our COPD patients live far away from the hospital, they cannot visit the hospital even once in every 2 weeks for 12 weeks. Therefore we enrolled them as a control group. The control group was followed regularly every 2 months or 3 months for medical care.

This study was performed from June 2001 to January 2003, and all patients gave informed consent.

\section{Method}

\section{1) Rehabilitation Programme}

The pulmonary rehabilitation programme lasted for 12 weeks, and consisted of education, exercise training, respiratory muscle training, and psychosocial and nutritional support. Psychosocial and nutritional support consisted of two lecture sessions by the psychiatrist and nutritionist. The control group received only psychosocial and nutritional support sessions with encouragement of regular exercise. Twelve weeks after the completion of the programme, patients in the rehabilitation group encouraged to continue the rehabilitation programme.

\section{Exercise Training}

The daily exercise training sessions comprised a warming-up (5-10 minutes), muscle strengthening using elastic bands (Therabands; Hygenic Inc., USA) (10 minutes), aerobic exercise (25 to 35 minutes), cooling down (5-10 minutes), and respiratory muscle training for 15 minutes. Patients were instructed to practice at least five days a week at home and to maintain a daily exercise diary. Patients visited the hospital every two weeks for readjustment of the exercise protocol, according to the results of repeated endurance tests and their health status.

\section{a) Aerobic exercise training by walking:}

A sport medicine specialist prescribed exercise training programmes according to the individual exercise capacity measured by the baseline incremental exercise test. Walking speed was calculated from the patient's $\mathrm{VO}_{2} \max$ using the following equation proposed by the American College of Sports Medicine [17].

\section{$\mathrm{VO}_{2} \max (\mathrm{ml} / \mathrm{mim})=\mathrm{X}(\mathrm{m} /$ minute $)$} $\times 0.1(\mathrm{ml} / \mathrm{kg} / \mathrm{meter})+3.5(\mathrm{ml} / \mathrm{kg}$ per minute $)$.

* $\quad 3.5 \mathrm{ml} / \mathrm{kg}$ per minute: oxygen consumption for the basal state;

* During walking, approximately $0.1 \mathrm{ml} \mathrm{O}_{2}$ consumption rate is needed for transporting each $\mathrm{kg}$ of body mass per meter $(\mathrm{m})$ of horizontal distance moved, i.e., $0.1 \mathrm{ml} / \mathrm{kg}$ per meter.

After calculation of the maximal speed (X $\mathrm{m} / \mathrm{min}$ ), one can estimate the number of steps the patient should walk in one minute by:

the number of steps in one minute $=\mathrm{X}(\mathrm{m} /$ minute $)$ /stride: individual stride length was measured at the hospital.

This is the maximal speed, and the exercise training was started from $60 \%$ of this speed for 25 minutes each day. However it is still very difficult for them to walk for 25 minutes without rest, at the beginning the patient had a rest at every 3 minutes. From the second week, the interval is progressively increased with the aim of walking 25 minutes without resting at the sixth week. For the following $7^{\text {th }}$ to $12^{\text {th }}$ week, the exercise duration is progressively increased to 35 minutes without rest. The patients could do exercise at any place, indoor or outdoor depending on the weather or their preference.

b) Respiratory muscle training was performed using a Threshold Inspiratory Muscle Trainer (HealthScan Products Inc; NJ, USA). The patients were instructed to start from a $30 \%$ intensity of MIP for 15 minutes twice a day, then gradually increase to achieve $60-70 \%$ of this value.

\section{2) Outcome Measure}

a) Lung function and exercise capacity.

$\mathrm{FVC}, \mathrm{FEV}_{1}$, and maximal inspiratory pressure (MIP) was tested. (SensorMedics; Vmax 22, USA). Diffusing capacity of carbon monoxide was measured by using the single-breath method (SensorMedics; Vmax 22, USA). Static lung volumes was measured by whole body plethysmography (SensorMedics; V6200). The symptomlimited maximal incremental exercise test was performed using a bicycle ergo meter (SensorMedics; 2900). In this protocol, the patients exercise on a cycle ergo meter while measurements of gas exchange are made at rest, during 3 minutes of very low level exercise, and then workload was increased with 10 Watts $/ \mathrm{min}$. Patients were instructed to stop when they could not continue the test any longer due to dyspnoea, general fatigue, or both. All patients scored the 
intensity of dyspnoea and leg effort on Borg category scale after finishing test. Sub-maximal endurance test of low extremity was performed using a cycle ergo meter (Monark; Ergomedic 818, Sweden) and started from $70 \%$ of the maximal work rate which was checked by maximal incremental exercise test. Also, upper extremity endurance tests using an arm ergo meter (Monark; Rehab trainer, 881E) was composed of 1 minute warming up and work rate was increased progressively for 5 watts every 2 minutes until patients was unable to continue.

Six minute walking distance was checked with measurement of oxygen saturation and heat rate during walking. All the tests were performed before the programme, at the conclusion of the programme (12 weeks). Six minute walking test and symptom-limited maximal incremental exercise test were performed one year after the completion of the programme.

\section{b) Quality of Life:}

Quality of life was measured by St George's Respiratory Questionnaire(SGRQ) before and after 12 weeks of the rehabilitation programme in both control and rehabilitation group. SGRQ is designed to quantify the impact of the disease of chronic airflow limitation on health and well-being and contains 76 items and is composed of three sections such as symptom, activity, and impact. The first symptom section, contains items concerned with the level of symptoms, including frequency of cough, sputum production, wheezes, breathlessness, and the duration and the frequency of attacks of wheezes or breathlessness. Activity section is concerned with physical activities that either cause or are limited by breathlessness. The final section of the questionnaire is the impact to social life by chronic airflow limitation. Each of the three sections of the questionnaire is scored separately in the range 0 to 100 , zero score indicating no impairment of life quality. A summary score utilising responses to all items is the total SGRQ score. This score also ranges from 0 to 100 [18]. The Korean translation of SGRQ was available and was kindly provided by Dr. SK Kim at Yeonsei University. It was validated in Korea as well as in other countries to quantify the impact of disease of chronic airflow limitation on health and well-being and to be sufficiently sensitive to respond to changes in disease severity [19].

\section{3) Statistical Analysis}

All analyses were performed with SPSS version 10.0 (SPSS Inc., Chicago, IL, USA). The baseline outcome measures between the two groups were compared using unpaired Student's $t$ tests, and the results before and after 12 weeks of rehabilitation or the follow-up data in the same group were compared using paired $t$-tests. All the data is presented as means \pm standard deviations and the significance level was set at $P<0.05$.

\section{Results}

\section{Demographic features of the subjects}

There were no significant differences between the rehabilitation ( 25 patients) and control groups (18 patients) in age, baseline pulmonary function parameters, arterial blood gas or MIP (table 1). No significant changes were found in pulmonary function parameters after 12 weeks in either group.

\section{Compliance}

Five patients dropped out of the rehabilitation group during the programme: three developed another disease not related to the original problem (gout, advanced gastric cancer and abdominal hernia); one patient had acute exacerbation of COPD during the initial study period, and one was noncompliant. Five patients dropped out of the control group, because of poor co-operation with the follow up evaluations. Twenty patients from the rehabilitation group and 13 from the control group completed the programme.

\section{The Efficacy of Home Rehabilitation}

\section{a) Changes in Exercise Capacity}

In the rehabilitation patients, maximal oxygen uptake and maximal work load were significantly improved after the rehabilitation programme, in contrast to the control group, which showed no significant change in any parameter (table 2). Dyspnoea and leg discomfort measured by a modified Borg scale showed no significant changes in either group. Sub-maximal endurance times and work of both the upper and lower extremities were significantly improved only in the rehabilitation group (Table 3). The six-minute walking distance and MIP were also significantly increased in the reha-

\begin{tabular}{lcc} 
Table 1. - Baseline Characteristics of the Study Population \\
\hline & Rehabilitation group & Control group \\
\hline Age (yrs) & $63.8 \pm 10.3$ & $64.4 \pm 5.4$ \\
FVC \% pred & $73.9 \pm 24.7$ & $79.1 \pm 16.0$ \\
$\mathrm{FEV}_{1} \%$ pred & $41.3 \pm 11.4$ & $39.7 \pm 12.8$ \\
$\mathrm{FEV}_{1} \mathrm{~L}$ & $1.1 \pm 0.3$ & $1.0 \pm 0.3$ \\
$\mathrm{FEV}_{1} / \mathrm{FVC}$ & $43.4 \pm 18.6$ & $35.2 \pm 7.9$ \\
$\mathrm{DL}_{\mathrm{CO}} \%$ pred & $66.7 \pm 19.6$ & $77.6 \pm 28.7$ \\
$\mathrm{TLC} \%$ pred & $109.8 \pm 31.7$ & $118.3 \pm 22.1$ \\
$\mathrm{RV} \%$ pred & $147.2 \pm 49.8$ & $159.6 \pm 44.8$ \\
$\mathrm{MIP}\left(\mathrm{cmH} \mathrm{H}_{2} \mathrm{O}\right)$ & $80.0 \pm 29.5$ & $89.8 \pm 29.8$ \\
$\mathrm{PaO}_{2} \mathrm{mmHg}$ & $80.8 \pm 14.2$ & $82.5 \pm 8.1$ \\
$\mathrm{PaCO}_{2} \mathrm{mmHg}$ & $36.4 \pm 5.7$ & $38.9 \pm 4.5$ \\
\hline
\end{tabular}

$\mathrm{TLC}=$ total lung capacity RV = residual volume; $\mathrm{MIP}=$ maximal inspiratory pressure 
bilitation but not the control group except small improvement of MIP (table 3).

b) Changes in Quality of Life

In the rehabilitation group, quality-of-life scores improved significantly after the programme. All dimensions except the symptom score were improved in the rehabilitation group. There was some improvement in impact and total score in the control group, although it was much less than in the rehabilitation group (table 4).

\section{Follow up Evaluation of Exercise Capacity}

Twelve months after the completion of the programme, 6 minute walking test and symptom-limited maximal incremental exercise test were performed. Four patients from rehabilitation group dropped out: one patient had acute exacerbation of COPD, two patients were lost during the follow-up and one patient transferred other hospital. Six patients from control group failed to attend the follow up evaluations. Sixteen patients from the rehabilitation group and seven from the control group

Table 2. - Changes in the Parameters of Incremental Exercise Test after the Rehabilitation

\begin{tabular}{|c|c|c|c|c|c|c|}
\hline \multirow[t]{2}{*}{ Variables } & \multicolumn{3}{|c|}{ Rehabilitation Group } & \multicolumn{3}{|c|}{ Control Group } \\
\hline & Baseline & 12 weeks & $p$ value & Baseline & 12 weeks & $p$ value \\
\hline WR max (watts) & $59.0 \pm 25.8$ & $65.0 \pm 26.4$ & 0.041 & $61.0 \pm 23.9$ & $60.8 \pm 22.0$ & NS \\
\hline $\mathrm{VO}_{2} \max (\mathrm{L} / \mathrm{min})$ & $0.85 \pm 0.31$ & $0.90 \pm 0.31$ & 0.027 & $0.89 \pm 0.32$ & $0.89 \pm 0.29$ & NS \\
\hline AT (L/min) & $0.74 \pm 0.22$ & $0.73 . \pm 0.24$ & NS & $0.80 \pm 0.18$ & $0.77 \pm 0.20$ & NS \\
\hline $\mathrm{O}_{2}$ pulse (ml/beat) & $7.64 \pm 3.26$ & $7.72 \pm 3.17$ & NS & $8.02 \pm 4.47$ & $7.13 \pm 2.06$ & NS \\
\hline HR max (beats/min) & $129.9 \pm 19.5$ & $131.6 \pm 17.3$ & NS & $138.6 \pm 27.7$ & $135.0 \pm 20.6$ & NS \\
\hline $\mathrm{V}_{\mathrm{E}} \max (\mathrm{L} / \mathrm{min})$ & $36.6 \pm 12.1$ & $38.1 \pm 11.1$ & NS & $33.8 \pm 11.7$ & $33.0 \pm 9.30$ & NS \\
\hline $\begin{array}{l}\text { Dyspnoea } \\
\text { (Borg scale) }\end{array}$ & $8.78 \pm 0.54$ & $8.78 \pm 0.78$ & NS & $8.15 \pm 1.28$ & $7.77 \pm 1.53$ & NS \\
\hline
\end{tabular}

WR $\max =$ maximal work rate; $\mathrm{VO}_{2} \max =$ maximum oxygen consumption; $\mathrm{AT}=$ anaerobic threshold $; \mathrm{HR}$ max $=$ maximum heart rate; $\mathrm{V}_{\mathrm{E}} \max =$ maximum minute ventilation.

Table 3. - Changes in the Exercise Endurance, 6 Minute Walking Distance and MIP after the Rehabilitation

\begin{tabular}{|c|c|c|c|c|c|c|}
\hline \multirow[t]{2}{*}{ Variables } & \multicolumn{3}{|c|}{ Rehabilitation Group } & \multicolumn{3}{|c|}{ Control Group } \\
\hline & Baseline & 12 weeks & $p$ value & Baseline & 12 weeks & $p$ value \\
\hline $\begin{array}{l}\text { Lower extremity } \\
\text { Duration (min) }\end{array}$ & $8.2 \pm 3.5$ & $14.0 \pm 4.5$ & 0.001 & $9.5 \pm 2.6$ & $10.4 \pm 2.9$ & NS \\
\hline Work (Watts) & $41.5 \pm 17.5$ & $46.5 \pm 19.0$ & 0.005 & $42.3 \pm 16.7$ & $43.4 \pm 15.8$ & NS \\
\hline $\begin{array}{l}\text { Upper extremity } \\
\text { Duration (min) }\end{array}$ & $5.9 \pm 3.2$ & $6.8 \pm 3.4$ & 0.001 & $6.8 \pm 4.13$ & $5.9 \pm 3.7$ & NS \\
\hline $\begin{array}{l}\text { Work (Watts) } \\
6 \text { min walk(m) } \\
{\mathrm{Mean} \mathrm{SaO}_{2} *}^{*} \\
\text { Min } \mathrm{SaO}_{2} * * \\
\text { MIP }\left(\mathrm{cm} \mathrm{H}_{2} \mathrm{O}\right)\end{array}$ & $\begin{aligned} 16.2 & \pm 8.0 \\
470.7 & \pm 63.2 \\
89.9 & \pm 5.50 \\
86.1 & \pm 7.12 \\
80.0 & \pm 29.5\end{aligned}$ & $\begin{array}{r}19.7 \pm 8.5 \\
508.4 \pm 61.1 \\
88.5 \pm 5.94 \\
83.8 \pm 7.66 \\
103.5 \pm 35.2\end{array}$ & $\begin{array}{c}0.001 \\
0.001 \\
\mathrm{NS} \\
\mathrm{NS} \\
0.001\end{array}$ & $\begin{array}{r}18.8 \pm 10.8 \\
494.0 \pm 63.4 \\
90.0 \pm 6.38 \\
85.8 \pm 8.68 \\
89.8 \pm 29.8\end{array}$ & $\begin{array}{r}17.3 \pm 9.2 \\
516.5 \pm 52.5 \\
88.6 \pm 5.69 \\
83.3 \pm 8.38 \\
99.6 \pm 31.0\end{array}$ & $\begin{array}{c}\text { NS } \\
\text { NS } \\
\text { NS } \\
\text { NS } \\
0.033\end{array}$ \\
\hline
\end{tabular}

* Mean $\mathrm{SaO}_{2}$ during 6 minute walk test; ** Minimal $\mathrm{SaO}_{2}$ during 6 minute walk test.

Table 4. - Changes in the Quality of Life (St. Georges Respiratory Questionnaire)

\begin{tabular}{lcccccc}
\hline Score & \multicolumn{3}{c}{ Rehabilitation Group } & \multicolumn{3}{c}{ Control Group } \\
\hline & Baseline & 12 weeks & $p$ value & Baseline & 12 weeks & $p$ value \\
\cline { 2 - 8 } Symptom & $45.6 \pm 19.6$ & $47.7 \pm 21.0$ & NS & $52.6 \pm 18.1$ & $48.4 \pm 20.7$ & NS \\
Activity & $64.3 \pm 16.2$ & $54.3 \pm 15.3$ & 0.001 & $62.3 \pm 12.7$ & $59.2 \pm 20.4$ & NS \\
Impact & $35.1 \pm 17.7$ & $20.8 \pm 13.8$ & 0.001 & $38.7 \pm 14.2$ & $30.6 \pm 12.3$ & 0.014 \\
Total & $45.7 \pm 14.6$ & $35.4 \pm 11.2$ & 0.001 & $48.2 \pm 11.6$ & $42.2 \pm 13.6$ & 0.017 \\
\hline
\end{tabular}


Table 5 - Follow Up Data of the Exercise Capacity 15 Months after Start of the Home Rehabilitation

\begin{tabular}{|c|c|c|c|c|c|c|}
\hline \multirow[t]{2}{*}{ Variables } & \multicolumn{3}{|c|}{ Rehabiltation group $(n=16)$} & \multicolumn{3}{|c|}{ Control group $(n=7)$} \\
\hline & baseline & 15 months & $p$ value & baseline & 15 months & $p$ value \\
\hline WR max (watts) & $63.1 \pm 24.8$ & $61.6 \pm 21.1$ & NS & $59.4 \pm 26.6$ & $52.9 \pm 20.4$ & NS \\
\hline $\mathrm{VO}_{2} \max (\mathrm{L} / \mathrm{min})$ & $0.87 \pm 0.32$ & $1.05 \pm 0.41$ & 0.005 & $0.85 \pm 0.31$ & $0.91 \pm 0.29$ & NS \\
\hline $\mathrm{AT}(\mathrm{L} / \mathrm{min})$ & $0.74 \pm 0.22$ & $0.84 \pm 0.24$ & 0.038 & $0.86 \pm 0.24$ & $0.87 \pm 0.26$ & NS \\
\hline $\mathrm{O}_{2}$ pulse (ml/beat) & $7.94 \pm 3.49$ & $8.76 \pm 3.12$ & NS & $9.16 \pm 5.71$ & $7.53 \pm 3.73$ & NS \\
\hline HR max (beat/min) & $132.3 \pm 17.8$ & $127.6 \pm 19.1$ & NS & $122.7 \pm 15.7$ & $119.1 \pm 22.1$ & NS \\
\hline $\mathrm{V}_{\mathrm{E}} \max (\mathrm{L} / \mathrm{min})$ & $37.0 \pm 12.2$ & $44.1 \pm 11.4$ & 0.008 & $33.7 \pm 13.2$ & $34.0 \pm 9.9$ & NS \\
\hline LE time $(\min ) *$ & $7.7 \pm 3.6$ & $13.2 \pm 3.8$ & 0.001 & $9.7 \pm 2.3$ & $12.2 \pm 3.1$ & NS \\
\hline LE work (Watts) & $44.1 \pm 17.1$ & $43.8 \pm 15.7$ & NS & $40.7 \pm 17.9$ & $37.9 \pm 15.5$ & NS \\
\hline 6MWD (m) & $481.6 \pm 62.9$ & $498.8 \pm 65.0$ & NS & $496.7 \pm 67.0$ & $508.6 \pm 46.0$ & NS \\
\hline
\end{tabular}

WR max = maximal work rate; $\mathrm{VO}_{2}$ max = maximum oxygen consumption; $\mathrm{AT}=$ anaerobic threshold; $\mathrm{HR}$ max = maximum heart rate; $\mathrm{V}_{\mathrm{e}} \mathrm{max}=$ maximum minute ventilation; $\mathrm{LE}=$ lower extremity; $6 \mathrm{MWD}=6$ minute walking distance; $*$ low extremity endurance time.

agreed to a re-evaluation. As shown in table 5, maximal oxygen consumption, maximal minute ventilation, anaerobic threshold and lower extremity endurance time were still significantly higher than the baseline values in the rehabilitation group. However, the six-minute walking distance and lower extremity workload returned to baseline values. In the controls, no parameters were significantly different from baseline.

\section{Discussion}

We have developed a simple, easy and cheap home-based exercise rehabilitation programme, which was well accepted by the patients. It improved the maximal exercise capacity, sub-maximal exercise endurance, six-minute walking distance, and health related quality of life of the patients with chronic lung diseases, despite no changes in pulmonary function. These results were similar to that of the intensive outpatient programme described in our previous report [20] and also in the literature [2-4, 21-23]. Because of many drop-outs in the follow up tests, long-term effects were not adequately evaluated, however the data suggested that the improvements in exercise endurance and maximum minute ventilation at the incremental exercise test lasted for 12 months after the completion of rehabilitation without a maintenance programme.

The outpatient hospital-based pulmonary rehabilitation programme is most commonly used and most of the efficacy of rehabilitation was proved in this mode. We also started the outpatient programme and found its effectiveness in exercise capacity and endurance, but it was not popularised in practice. For the outpatients programme to be effective, patients should visit hospital at least three times a week for 6-8 weeks, which is a great burden on the patients and their families, because severely disabled patients cannot attend the sessions by themselves. In our experience, it is impractical for most patients living not only in rural areas but also in cities with heavy traffic. Because the out- patient rehabilitation programme demands much space, expensive equipments and many personnel in the hospital and it is not reimbursed by medical insurance in Korea, it caused a financial burden to the hospital. Furthermore many of the benefits achieved by the rehabilitation decline progressively after the cessation of exercise training [6-10].

Therefore, there is a need for a home-based programme, which has a definite advantage for the patients and also the hospital. However there are only a few reports about home-based rehabilitation programmes. McGavin [11] reported that progressive stair-climbing exercises for three months resulted in improvement of 12-minute walking distance and a degree of work tolerated in a progressive workload test on a bicycle ergo meter. Wijkstra et al [12-14] found that home rehabilitation for 12 weeks in patients with COPD could improve their exercise tolerance and health-related quality of life as measured by a chronic respiratory questionnaire, even though the six-minute walking distance was not improved. Strijbos et al [15] compared the effect of a home-based programme with an outpatient programme. Although the two programmes produced equal improvements in exercise capacity and Borg dyspnoea scores three to six months after the start of the rehabilitation, in the outpatient programme, long-term values tended to decrease and return to baseline. By contrast, the home programme led to an ongoing significant improvement in exercise capacity and four-minute walking distance. The quality of life was not measured in this study. These results suggested that improvements were significantly better maintained after a home rehabilitation programme. However, both of their programmes were very complex, intense and very well supervised, and therefore not entirely home-based. The exercise training was supervised by a local physiotherapist twice a week during the whole period of 12 weeks, and the patients were visited three times by a home-care nurse and also seen three times by a general practitioner. Later Hernandez et al [16] developed a simple home-based rehabilitation programme us- 
ing a shuttle-walking test. They found a twofold increase in the sub-maximal intensity resistance test with less dyspnoea despite no significant improvement in maximal effort parameters such as oxygen consumption. They concluded that this home-based programme achieved a significant improvement in exercise tolerance, post-effort dyspnoea, basal dyspnoea, and quality of life in their patients. The shuttle-walking test is a maximal, incremental, and externally paced exercise test. In this programme patients were requested to walk between two cones placed 20 metres apart with the walking speed progressively increasing each minute according to tape recorded pacing. This programme needs space and a tape recorder and is therefore not so easy for the patient. Indeed, the main reason for dropping out among the rehabilitation patients in that study was the difficulty of finding a suitable training site. Although the site was checked in advance, sometimes the patients were uncomfortable and decided not to continue. By contrast, our programme is simple and requires no equipment or special location. All the patients need to do is to count the number of steps in one minute, and rest after walking for a certain amount of time. The second time, the patient can use the landmark instead of counting the steps. They can do at any place and at any time. The advantage of our programme was reflected in the low dropout rate. Even though five of the patients (20\%) dropped out of the rehabilitation group, this was mainly due to the development of other diseases during the rehabilitation period, and only one patient dropped out owing to poor compliance. And our result showed that this simple programme of walking at home adjusted for individual exercise capacity could achieve results comparable with intensive outpatient rehabilitation including quality of life. There are several different tests for measuring health-related quality of life in patients with COPD, of which the Chronic Respiratory Questionnaire and the St George's Respiratory Questionnaire have been demonstrated to be reproducible, valid, and responsive [24]. Each component of the questionnaires gives a weighted score between 0 and 100 including the total, with normal values in healthy individuals of less than seven points for each component. A change of four points in the total score represents the minimum clinically significant change [18]. Thus, our 10.3 point reduction in total scores after rehabilitation shows the clinically significant benefits of our programme. All the component sections except for the symptom score (activity, impact and total score) showed highly significant improvements in the rehabilitation group, in concordance with the report of Foglio [6]. The lack of change in the symptom score might be due to stable state of the patients in this study under optimal medical therapy. The total and impact scores improved slightly but significantly, even in our control group, which might be related to the effect of education, and other support session. However, the degree of improvement was much larger in the rehabilitation group than in the control group. The major limitation of our study is the small number of subjects, especially at the time of follow-up examination, some patients dropped out. Therefore we cannot adequately evaluate the long-term effect at this time. But, significant improvement in the lower extremity endurance was well maintained up to one year after the completion of the training without a further maintenance programme.

In conclusion, we developed a simple and easy home based rehabilitation programme and we found that our programme was both well accepted by the patients and effective. Further research is required to demonstrate the long-term effect of this home-based pulmonary rehabilitation programme.

\section{References}

1. Morgan MDL, Calverley PMA, Clark CJ. Standards of Care Subcommittee on Pulmonary Rehabilitation. British Thoracic Society. Thorax 2001; 56: 827-834.

2. ACCP/AACVPR. Pulmonary Rehabilitation Guideline Panel. Pulmonary Rehabilitation: Joint ACCP/AACVPR Evidence-Based Guidelines. Chest 1997; 112: 13631396.

3. American Thoracic Society. Pulmonary Rehabilitation1999. Am J Respir Crit Care Med 1999; 159: 16661682.

4. Yves L, Eric W, Gordon HG. Meta-analysis of respiratory rehabilitation in chronic obstructive pulmonary disease. Lancet 1996; 348: 1115-1119.

5. Gómez FP. Global Initiative for Chronic Obstructive Lung Disease (GOLD) guidelines for chronic obstructive pulmonary disease. Curr Opin Pulm Med 2002; 8: 81-86.

6. Foglio K, Bianchi L, Bruletti G. Long-term effectiveness of pulmonary rehabilitation in patients with chronic airway obstruction. Eur Respir J 1999; 13: 125-132.

7. Ries AL, Kaplan RM, Limberg TM. Effects of pulmonary rehabilitation on physiologic and psychosocial outcomes in patients with chronic obstructive pulmonary disease. Ann Intern Med 1995; 122: 823-832.

8. Ries AL, Kaplan RM, Myers M. Maintenance after Pulmonary Rehabilitation in Chronic Lung Disease: A Randomized Trial. Am J Respir Crit Care Med 2003; 167: 880-888.

9. Bestall JC, Paul EA, Garrod R. Longitudinal trends in exercise capacity and health status after pulmonary rehabilitation in patients with COPD. Respir Med 2003; 97: $173-180$.

10. Guell R, Casan P, Belda J. Long-term effects of outpatient rehabilitation of COPD: A Randomized Trial. Chest 2000; 117: 976-983.

11. McGavin CR, Gupta SP, Lloyd EL. Physical rehabilitation for the chronic bronchitic. - results of a controlled trial of exercises in the home. Thorax 1977; 32: 307311.

12. Wijkstra PJ, Van Altena R, Kraan J. Quality of life in patients with chronic obstructive pulmonary disease improves after rehabilitation at home. Eur Respir J 1994; 7: 269-273.

13. Wijkstra PJ, Ten Vergert EM, Van Altena R. Long term benefits of rehabilitation at home on quality of life and exercise tolerance in patients with chronic obstructive pulmonary disease. Thorax 1995; 50: 824-828.

14. Wijkstra PJ, Van der Mark, Krran J. Long-term effects of home rehabilitation on physical performance in chronic obstructive pulmonary disease. Am J Respir Crit Care Med 1996; 153: 1234-1241.

15. Strijbos JH, Postma DS, Van Altena R. A comparison 
between an outpatient hospital-based pulmonary rehabilitation programme and a home-care pulmonary rehabilitation programme in patients with COPD. A followup of 18 months. Chest 1996; 109: 366-372.

16. Hernandez MT, Rubio TM, Ruiz FO. Results of a home-based training programme for patients with COPD. Chest 2000; 118: 106-114.

17. Lippincott W, Wilkins. ACSM's Guidelines for exercise testing and prescription. 6th ed. Am College of Sports Med 2000; 300-312.

18. Jones PW, Quirk FH, Baveystock CM. The St, George's Respiratory Questionnaire. Respir Med 1991; 85: Suppl. B, 25-31.

19. YS Kim, JW Moon, MS Park, et al. Validity and reliability of the Korean version of the St George's respiratory questionnaire-pilot study. Eur Respir J 2003; 22: Suppl. 45, 241s.
20. Choi KH, Park YJ, Cho WK, et al. Effect of pulmonary rehabilitation in the patients with chronic lung diseases. Tuberculosis and Respiratory Disease (Korean) 1996; 43: 736-745.

21. Readon J, Award E, Vale F, et al. The effect of comprehensive outpatients pulmonary rehabilitation on dyspnoea. Chest 1994; 105: 1046-1052.

22. Finnerty JP, Keeping I, Bullough I, et al. The Effectiveness of outpatient pulmonary rehabilitation in chronic lung disease. Chest 2001; 119: 1705-1710.

23. Troosters T, Gosselink R, Decramer M. Short-and longterm effects of outpatient rehabilitation in patients with chronic obstructive pulmonary disease: a randomized trial. Am J Med 2000; 109: 207-212.

24. Cutis JR, Deyo RA, Hudson LD. Health-related quality of life among patients with chronic obstructive pulmonary disease. Thorax 1994; 49: 162-170.

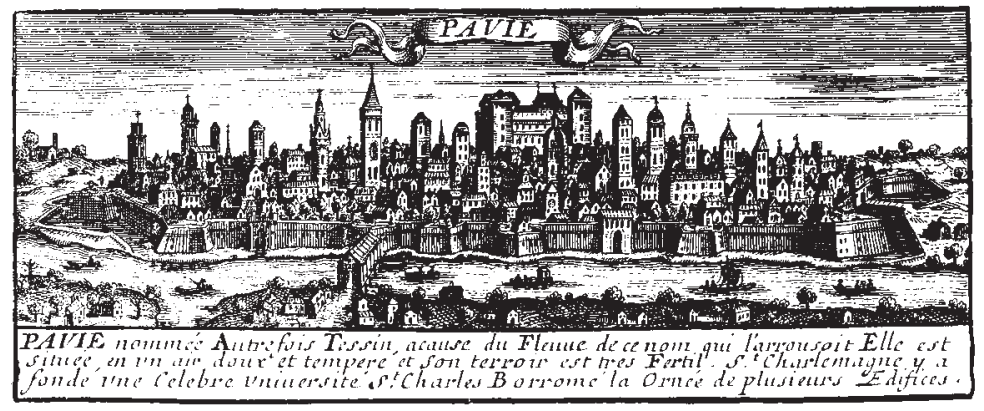

